\section{International Scientific Journal Theoretical \& Applied Science}

\author{
p-ISSN: 2308-4944 (print) e-ISSN: 2409-0085 (online) \\ Year: 2016 Issue: 8 Volume: 40 \\ Published: $30.08 .2016 \quad$ http://T-Science.org
}

\begin{abstract}
Master of Engineering and Technology, Corresponding
Member of International Academy of Theoretical and Applied Sciences, Lecturer of Vladimir Industrial College, Russian Federation chemezov-da@yandex.ru
\end{abstract}

SECTION 7. Mechanics and machine construction.

\title{
FORMATION OF THE CYLINDRICAL HOLLOW DETAIL BY THE METHOD OF DRAWING WITH THINNING OF THE SIDE WALL OF THE SEMI-FINISHED PRODUCT
}

Abstract: The article is presented the sequence of the technological process of drawing with thinning of the side wall of the semi-finished product. The dimensions of the processed hollow detail when the elongation ratio equal to 1.5 are defined.

Key words: drawing with thinning, side wall, dimension, die, elongation ratio, semi-finished product.

Language: Russian

Citation: Chemezov D (2016) FORMATION OF THE CYLINDRICAL HOLLOW DETAIL BY THE METHOD OF DRAWING WITH THINNING OF THE SIDE WALL OF THE SEMI-FINISHED PRODUCT. ISJ Theoretical \& Applied Science, 08 (40): 15-18.

Soi: http://s-o-i.org/1.1/TAS-08-40-3 Doi: crossef http://dx.doi.org/10.15863/TAS.2016.08.40.3

\section{ФОРМООБРАЗОВАНИЕ ЦИЛИНДРИЧЕСКОЙ ПУСТОТЕЛОЙ ДЕТАЛИ МЕТОДОМ ВЫТЯЖКИ С УТОНЕНИЕМ БОКОВОЙ СТЕНКИ ПОЛУФАБРИКАТА}

Аннотация: В статье представлена последовательность выполнения технологического процесса вытяжки с утонением боковой стенки полуфабриката. Определены размеры обработанной пустотелой детали при коэффициенте вытяжки равном 1.5.

Ключевые слова: вытяжка с утонением, боковая стенка, размер, матрица, коэффициент вытяжки, полуфабрикат.

Вытяжка с утонением применяется для получения пустотелых деталей с переменной толщиной боковой стенки [1]. За один проход рекомендуется уменьшение толщины боковой стенки не более чем на $50 \%$ от исходной толщины предварительно обработанной давлением заготовки (полуфабриката). Вытяжке подвергают пластичные материалы, преимущественно металлические сплавы. Вытяжка с утонением выполняется в вытяжном штампе посредством формообразующих инструментов: цилиндрического пуансона и матрицы со ступенчатым рабочим отверстием [2, c. $37 ; 3$, с. 26]. Пустотелую цилиндрическую заготовку, изготовленную вытяжкой без утонения [4; 5], устанавливают дном в коническое отверстие матрицы. Давление торцевой поверхностью пуансона происходит на внутреннюю торцевую поверхность дна полуфабриката. Толщина дна полуфабриката должна быть больше, чем исходная толщина боковой стенки. Наружная поверхность дна полуфабриката не должна выходить за пределы деформирующего участка отверстия матрицы во избежание неполного утонения боковой стенки.

Компьютерное моделирование позволяет в виртуальном режиме, приближенном к реальному физическому процессу, получить представление о динамике пластического деформирования материалов давлением и выполнить анализ результатов расчета. Для этого принимаются следующие условия выполнения технологического процесса вытяжки с утонением боковой стенки полуфабриката:

$$
\left\{\begin{array}{l}
\varepsilon_{1}=0 \\
\varepsilon_{2}=0 \\
0<\varepsilon_{3}>1
\end{array},\right.
$$

где $\varepsilon_{1}-$ степень пластической деформации пуансона, изготовленного из инструментальной штамповой стали [6]; $\varepsilon_{2}-$ степень пластической деформации матрицы, изготовленной из 
инструментальной штамповой стали; $\varepsilon_{3}-$ степень пластической деформации заготовки, изготовленной из конструкционной стали [7].

$$
\left\{\begin{array}{l}
v_{p}=\text { const }, v_{p}>0 \\
v_{d}=0
\end{array},\right.
$$

где $v_{p}$ и $v_{d}$ - скорости движения пуансона и матрицы соответственно, м/мин. Скорость движения полуфабриката при обработке равна скорости движения пуансона.

$$
0<P \geq 0.4
$$

где $P$ - расчетная величина усилия вытяжки с утонением боковой стенки, кН.

$$
K=\frac{S_{0}}{S_{1}}
$$

где $K$ - коэффициент вытяжки с утонением [8]; $S_{0}$ - толщина боковой стенки заготовки, мм; $S_{1}-$ толщина боковой стенки обработанной детали, MM. a)

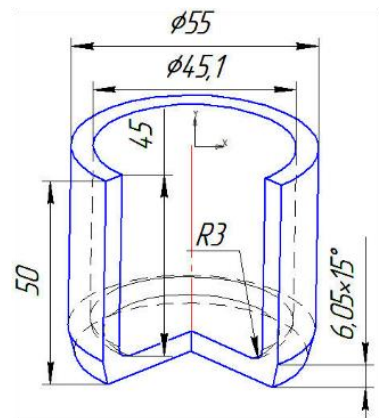

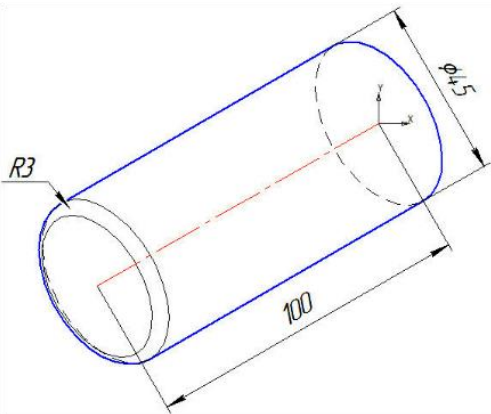

б)

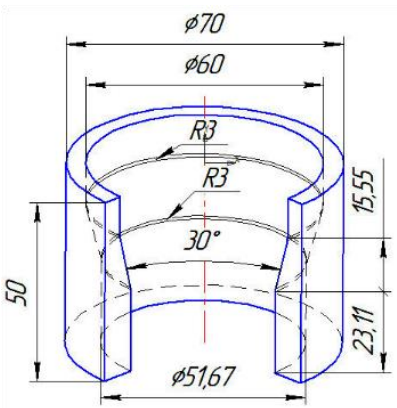

B)
Рисунок 1 - Конфигурация и размеры полуфабриката (а), пуансона (б) и вытяжной матрицы (в).
Толщина боковой стенки полуфабриката до обработки давлением принималась величиной 5 мм. Время расчета составило 15 ч.

Последовательность технологического процесса вытяжки с утонением стенки полуфабриката в 1.5 раза представлена на рис. 2 .

Движение пуансона в вертикальном направлении приводит к перемещению заготовки вдоль осевой линии ступенчатого отверстия вытяжной матрицы. На коническом участке ступенчатого отверстия вытяжной матрицы происходит пластическая деформация боковой стенки полуфабриката, приводящая одновременно к сжатию и растяжению материала на всем временном диапазоне выполнения технологического процесса вытяжки с утонением. Тем самым уменьшается наружный диаметр и увеличивается высота тонкостенной детали без изменения размеров внутреннего диаметра и дна.

После вытяжки с утонением боковой стенки полуфабриката высота тонкостенной пустотелой детали составила 66.39 мм. Это на $32.8 \%$ больше исходной высоты полуфабриката. При соответствующем $K$ ожидаемая толщина боковой

$$
S=S_{0}-S_{1},
$$

где $S$ - зазор между контактными поверхностями матрицы и пуансона, мм. вязкости принимались величинами 1.5 и 0.06 соответственно. Расчет энергии производился для процедуры обработки искажений конечных элементов по типу песочных часов. В общий баланс энергии включались: диссипация энергии по границе скольжения контактов и рэлеевское рассеяние энергии [9, 374 - 375]. Коэффициент трения скольжения для пары материалов конструкционная сталь - инструментальная штамповая сталь (контакт «пуансон полуфабрикат» и «матрица - полуфабрикат») принят величиной 0.11 .

Конфигурация и размеры полуфабриката, пуансона и вытяжной матрицы представлены на рис. 1.
Квадратичный и линейный коэффициенты

стенки детали должна составлять 3.33 мм. Измерение показало изменение толщины боковой стенки обработанной детали от 3.5 мм до 3.96 мм. Увеличение толщины боковой стенки после обработки детали давлением происходит от упругопластической деформации материала (тонкостенная деталь частично принимает первоначальные форму и размеры полуфабриката).

Коэффициент пластической деформации материала полуфабриката составляет 0.865 в калибрующей зоне (цилиндрический участок) вытяжной матрицы, что в 2.5 раза больше, чем пластическая деформация материала листовой заготовки при вытяжке без утонения прямым способом. Минимальная величина пластической деформации наблюдается в области дна полуфабриката. Величина усилия вытяжки с утонением должна приниматься большей, чем при вытяжке без утонения, т. к. площадь контактирующих поверхностей (полуфабриката и деталей штампа) увеличивается со временем.

Для более точного моделирования процесса вытяжки с утонением боковой стенки рекомендуется применять модель пластичности 


\begin{tabular}{|c|c|c|c|c|c|c|}
\hline Impact Factor: & $\begin{array}{l}\text { ISRA (India) } \\
\text { ISI (Dubai, UAE } \\
\text { GIF (Australia) } \\
\text { JIF }\end{array}$ & $\begin{array}{l}=1.344 \\
=0.829 \\
=0.564 \\
=1.500\end{array}$ & $\begin{array}{l}\text { SIS (USA) } \\
\text { PИНЦ (Russia) } \\
\text { ESJI (KZ) } \\
\text { SJIF (Morocco) }\end{array}$ & $\begin{array}{l}=0.912 \\
=0.234 \\
=1.042 \\
=2.031\end{array}$ & $\begin{array}{l}\text { ICV (Poland) } \\
\text { PIF (India) } \\
\text { IBI (India) }\end{array}$ & $\begin{array}{l}=6.630 \\
=1.940 \\
=4.260\end{array}$ \\
\hline
\end{tabular}

Джонсона/Кука, учитывающую деформацию и изменение температуры материала заготовки
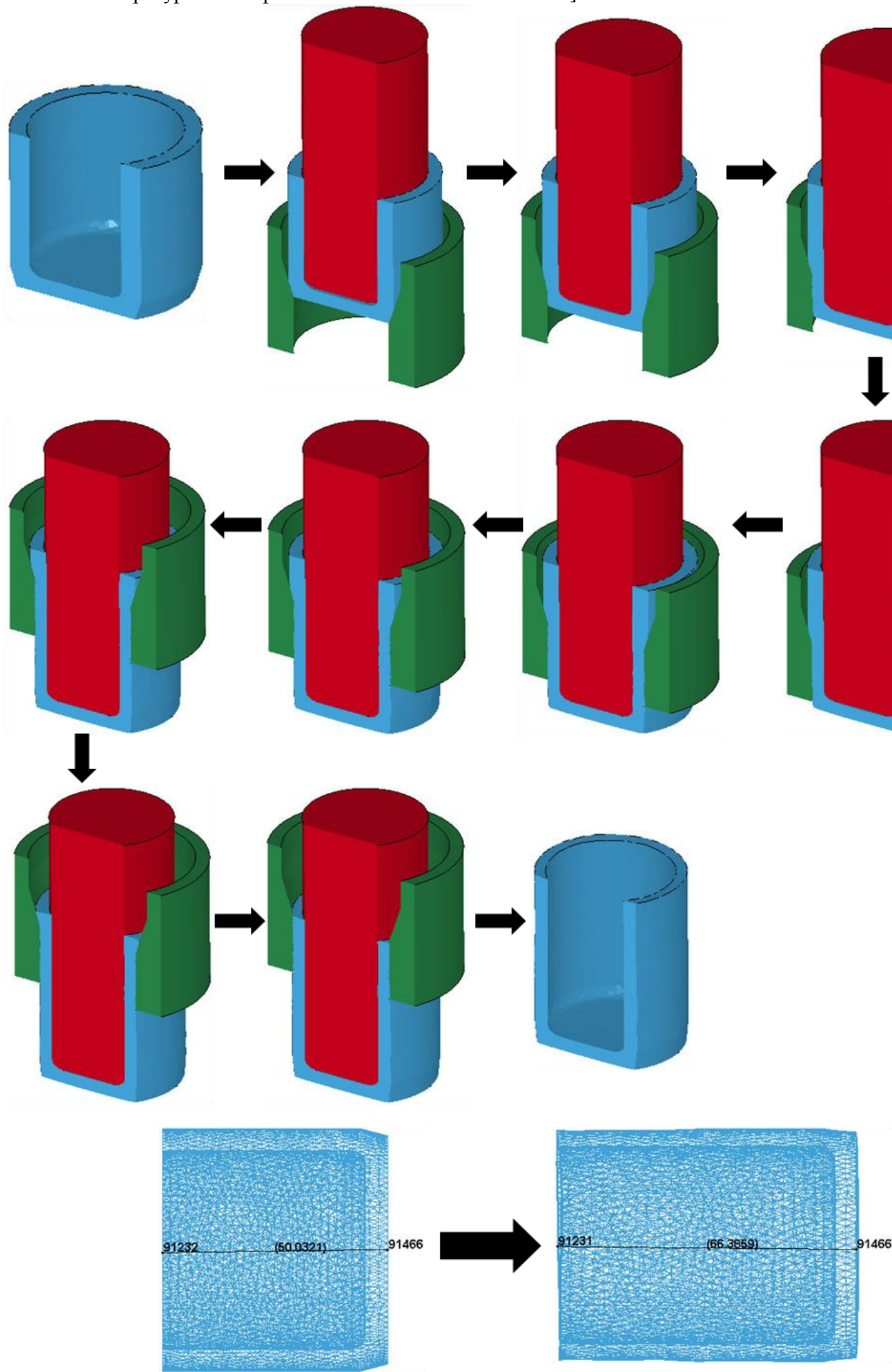

Рисунок 2 - Последовательность технологического процесса вытяжки с утонением стенки и размеры высоты полуфабриката и обработанной пустотелой детали.

ISPC The development of applied research, 


\begin{tabular}{l|lrl|l|ll} 
& ISRA (India) & $=\mathbf{1 . 3 4 4}$ & SIS (USA) & $=\mathbf{0 . 9 1 2}$ & ICV (Poland) & $=\mathbf{6 . 6 3 0}$ \\
Impact Factor: & ISI (Dubai, UAE) $=\mathbf{0 . 8 2 9}$ & PUHIL (Russia) $=\mathbf{0 . 2 3 4}$ & PIF (India) & $=\mathbf{1 . 9 4 0}$ \\
& GIF (Australia) & $\mathbf{0 . 5 6 4}$ & ESJI (KZ) & $=\mathbf{1 . 0 4 2}$ & IBI (India) & $\mathbf{= 4 . 2 6 0}$ \\
& JIF & $\mathbf{1 . 5 0 0}$ & SJIF (Morocco) & $=\mathbf{2 . 0 3 1}$ & & \\
\hline
\end{tabular}

\section{References:}

1. (2016) Vytyazhka zagotovki. Available: http://промпортал.su/vitagka (Accessed: 14.08.2016).

2. Bilibin KI (2010) Cold stamping: the textbook for the course "Technology of electronic means". Publishing of Moscow State Technical University named after N.E Bauman, 2010. $68 \mathrm{p}$.

3. Skhirtladze AG, Morozov VV, Zhdanov AV, Zalesnov AI (2007) Computer-aided design of dies. Publishing of Vladimir State University, 2007. - 284 p.

4. Chemezov DA, Seliverstov VS, Komisar AS, Zezina NA, Tyurina SI (2015) Stamping of the plate stock with blank holder: the character of the material deformation and calculation of the coefficient of elongation. ISJ Theoretical \& Applied Science 11 (31): 101-107. Soi: http://so-i.org/1.1/TAS-11-31-16 Doi: http://dx.doi.org/10.15863/TAS.2015.11.31.16

5. Chemezov DA (2016) The calculation of the maximum stress of thin-walled detail while performing the technological process of deep drawing of the plate stock. XIII International scientific-practical conference "Fundamental and applied researches in the modern world". Vol. 1. - pp. 36 - 39. ISSN 2307-1354.

6. (2016) Shtampovye stali. Available: https://ru.wikipedia.org/wiki/Штамповые стал и (Accessed: 14.08.2016).

7. (2016) Konstruktsionnaya stal'. Available: https://ru.wikipedia.org/wiki/Конструкционная сталь (Accessed: 14.08.2016).

8. Orlova E, Urazaev D (2015) Design procedure of two-operational technology of the combined extract. Vestnik of KazNRTU, №2 (108), Technical Sciences. - pp. $72-80$.

9. LS-DYNA. KEYWORD USER'S MANUAL (VOLUME I). - Livermore Software Technology Corporation, 2001.

10. LS-DYNA. KEYWORD USER'S MANUAL (VOLUME II). - Livermore Software Technology Corporation, 2001. 